\title{
ASSESSMENT OF EMBRYO PRODUCTION OF DROMEDARY (Camelus dromedarius) USING TWO SEMEN SOURCES AND TWO IN VITRO FERTILIZATION TECHNIQUES
}

\author{
A. El-Sayed ${ }^{1,2}$, G. Ashour ${ }^{1}$, A.M. Kamel ${ }^{3}$, K.A. El-Bahrawy ${ }^{3}$ \\ 1- Department of Animal Production, Faculty of Agriculture, Cairo University, 12613, Giza, Egypt, \\ 2- Cairo University Research Park (CURP), Faculty of Agriculture, 12613 Giza, Egypt, \\ 3- Animal and Poultry Production Division, Desert Research Center, Cairo, Egypt.
}

\section{SUMMARY}

The current study was conducted to evaluate the effects of maturation time (30 or 40 hours) on maturation rate (\%) and two sources of spermatozoa; epididymal spermatozoa $(G 1)$, frozen semen (G2) and two insemination methods IVF (G1 and G2) and intra-cytoplasmic sperm injection (ICSI) (G3) on the cleavage rate and development competence of in vitro produced embryos as a trial to improve the reproductive efficiency of the dromedary camel. Cumulus oocytes complexes (COCs) were recovered from ovaries by slicing technique. Based on morphological characteristics (number of cumulus cells enclosed the oocytes and the clearance of the cytoplasm) only grade $A$ and $B$ oocytes were selected to be cultured in TCM-199 medium for maturation at 5\% CO2 and $38.5^{\circ} \mathrm{C}$ for 30 or 40 hours. According to maturation results, the mature oocytes were subjected to two sources of spermatozoa. For G1, a number of 205 oocytes were inseminated with fresh epididymal spermatozoa $\left(1 \times 10^{6}\right.$ spermatozoa/ml). In G2, a number of 290 oocytes were inseminated with frozen thawed semen $\left(3 \times 10^{6}\right.$ spermatozoa/ml). Whereas in G3, 28 oocytes were denuded and inseminated (individually injected) by ICSI technique. The results showed a significantly $(P \leq 0.05)$ higher maturation rate $(83 \%)$ in oocytes subjected to $30 \mathrm{~h}$ compared to $40 \mathrm{~h}$ group (64\%). There was no significant $(P>0.05)$ difference in cleavage rate between the three groups being 21, 20 and $23 \%$ for G1, G2 and G3, respectively. Blastocyst rate calculated to fertilized oocytes was higher in G1 (8.27\%) and G2 (8.33\%) compared to G3 (5.5\%). In conclusion, this study validates the first application of the ICSI technique as a successful method for embryo production in dromedary camel. Moreover, there is no difference between frozen and epididymal spermatozoa on blastocyst rate when applying in vitro fertilization.

Keywords: Dromedary, Fertilization protocols, ICSI, Oocytes, Embryo production

\section{INTRODUCTION}

Dromedary camel is considered a multipurpose animal. It is used for milk, meat productions, transport and sports (Skidmore, 2005). In Egypt, despite of its major important and high potential value, camel participate a small part in agriculture system for meat production with 47250 ton/year (FAO, 2013).

The reproductive efficiency of camels under natural conditions is approximately $40 \%$, this is probably due to the relatively short breeding season, long pre-pubertal period, long gestation period, prolonged lactation period and the lack of use of assisted reproductive techniques (Skidmore, 2005).

In vitro embryo production technology (IVP) has been successfully applied to number of animal species with different success rate (Gordon, 2003). The purposes of produced embryos vary from commercial to research such as studies the pre-implantation development and application of new technologies. However, there is still a lack of application of such technique in camels (Skidmore, 2005).
Many trails were conducted to study the possibility of success of in vitro oocyte maturation in camelids and dromedary (Abdoon, 2001; Torner et al., 2003; Khatir et al., 2004; Nowshari and Wani, 2005; Khatir and Anouassi, 2006 and El-Sayed et al., 2012) indicating that preparation of semen and culture media are restricting the success on in vitro embryo production.

Previous works aimed at reaching an appropriate protocol for in vitro camels' embryo production. The results indicated that the success rate of reaching to blastocyst stage ranged from 14 to 23\% (Khatir and Anouassi, 2006; Abdoon et al., 2007 and Wani, 2009).

Semen preparation is one of the corner stone's on in vitro embryo production in camels. Different methods were used to separate good motile sperm to be used in in vitro fertilization step (Suthar and Shah, 2009). Fresh ejaculated spermatozoa have been used for IVF of dromedary oocytes with blastocyst rate up to 23\% (Khatir et al., 2004 and 2005), reduced to $17 \%$ when epididymal spermatozoa were used after storing in tris extender (Nowshari and Wani, 2005). Up to the knowledge of the authors 
rare data are available to describe the success rate of camel's embryo production using frozen semen and little has done applying intracytoplasmic sperm injection (ICSI). This one is a powerful technique in the field of assisted reproduction technologies (ART). It implies the injection of the spermatozoa inside an oocyte, bypassing the natural process of sperm-oocyte interaction. It could be used in livestock species to solve the fertilization problems in IVF systems (García-Roselló et al., 2009). Moreover, it can be very useful to use the sex-sorted semen in which spermatozoa are low in numbers and motility (Probst and Rath, 2003).

In this context, the current study was conducted to evaluate the effect of two sources of spermatozoa (epididymal spermatozoa and frozen semen) and two techniques of fertilization (intra-cytoplasmic sperm injection and in vitro fertilization) on the cleavage rate and development competence of in vitro produced embryos of dromedary camel.

\section{MATERIALS AND METHODS}

\section{Chemicals and media:}

Unless otherwise mentioned, all the chemicals and media constituents were purchased from Sigma-Aldrich Chemicals, Germany.

Dromedary camel frozen semen was obtained from artificial insemination and embryo transfer lab - Marriott Research Station - Desert Research Center, Alexandria, Egypt.

\section{In vitro maturation of oocytes:}

A number of 376 dromedary camel ovaries were collected from two abattoirs (El-Bassatein and El-warrak).The collected ovaries were placed immediately after slaughtering into thermo flask contains normal saline solution $(0.9 \% \mathrm{NaCl})$ supplemented with antibiotic (100 IU penicillin and $100 \mu \mathrm{g}$ streptomycin/ml) at 25 $30{ }^{\circ} \mathrm{C}$ and transported to the laboratory (Cairo University Research Park, Cairo University, Giza, Egypt) within two to four hours from slaughtering. Then, ovaries were washed once with ethanol (70\%) to remove any contamination. Followed by final washing with pre-warmed $\left(30{ }^{\circ} \mathrm{C}\right)$ phosphate buffered saline (PBS) supplemented with antibiotics (100 IU penicillin and $100 \mu \mathrm{g}$ streptomycin/ml). All visible follicles on the ovarian surface $(2-8 \mathrm{~mm}$ diameter) were sliced using normal sharp razor in a glass petri dish contains pre-warmed $\left(30{ }^{\circ} \mathrm{C}\right)$ PBS. The harvesting medium containing the COCs transferred to glass tubes for $10 \mathrm{~min}$ for precipitation. Searching for COCs and grading has been done under stereo microscope (MZ6, Leica Microsystems, Wetzlar, Germany). Only good quality oocytes were selected and washed three times in washing medium (TCM-199 with
HEPES - Gibco, Grand Island, NY, USA) supplemented with $10 \%$ (v/v) heat-treated $\left(56^{\circ} \mathrm{C}\right.$ for $30 \mathrm{~min})$ fetal bovine serum(FBS) and antibiotic(100 IU penicillin and $100 \mu \mathrm{g}$ streptomycin/ml). Then, once in IVM medium (TCM-199 HEPES free - Gibco, Grand Island, NY, USA) supplemented with $0.3 \%$ Cysteine, $10 \%$ FBS, $10 \mu \mathrm{g} / \mathrm{ml} \mathrm{FSH,} 10 \mu \mathrm{g} / \mathrm{ml} \mathrm{LH}, 20$ $\mathrm{ng} / \mathrm{ml} \mathrm{EGF,} 0.25 \mathrm{mg} / \mathrm{ml} \mathrm{Na}{ }^{+}$pyruvate and 1 $\mathrm{mg} / \mathrm{ml}$ estradiol and antibiotic (100 IU penicillin and $100 \mu \mathrm{g}$ streptomycin/ml) as final washing. Maturation medium was sterilized using $0.22 \mu \mathrm{m}$ millipore syringe filters and incubated in $\mathrm{CO}_{2}$ incubator two hours before using (Amer and Moosa, 2008). The oocytes were placed in four well plate each well contains 25 - 30 oocytes in $400 \mu \mathrm{l}$ of IVM medium and covered with mineral oil then incubated in $\mathrm{CO}_{2}$ incubator at $38.5{ }^{\circ} \mathrm{C}$ in $5 \% \mathrm{CO}_{2}$ and humidity $95 \%$ in the air for 30 or 40 hours depending on the experiment.

\section{Semen preparation:}

For epididymal spermatozoa, testicles were collected within their scrotum under hygienic conditions and transported to the laboratory within one hour in an ice box at temperature between $25-30{ }^{\circ} \mathrm{C}$ using water bags. Each testicle was dissected away from its tunica vaginalis and other extraneous tissues, washed 3 times by tab water and once by alcohol $70 \%$. Various incisions in the tail of epididymis were performed with a scalpel and then, the spermatozoa were released and allowed to swim out by gently pressing that region manually in 6 $\mathrm{cm}$ petri dish containing $5 \mathrm{ml}$ sperm TALP (Parrish et al., 1986), for five to $10 \mathrm{~min}$. The recovered spermatozoa were placed in $15 \mathrm{ml}$ falcon tube in water bath at $37^{\circ} \mathrm{C}$. For IVF, the sperm suspension was washed twice with sperm TALP by centrifugation at $250 \times \mathrm{g}$ for $10 \mathrm{~min}$ each. The pellet was overlaid with fertilization medium (TALP supplemented with $4 \mathrm{mg} / \mathrm{ml}$ BSA, $50 \mathrm{IU} / \mathrm{ml}$ penicillin and $10 \mu \mathrm{g} / \mathrm{ml}$ heparin) and allowed to swim up for 1 hour in an incubator $\left(5 \% \mathrm{CO}_{2}\right.$ and $\left.38.5^{\circ} \mathrm{C}\right)$ with angle of 45 degree. The motile spermatozoa were added to the oocytes at the concentration of approximately $1 \times 10^{6} / \mathrm{ml}$ (Wani, 2009).

For frozen semen, two $0.5 \mathrm{ml}$ straws were thawed in water bath at $37^{\circ} \mathrm{C}$ for 40 seconds (ElBhrawi, 2005). Straws were wiped with $70 \%$ ethyl alcohol before being opened. The content over layered on $5 \mathrm{ml}$ of sperm washing medium (Sperm TALP medium) in a $15 \mathrm{ml}$ falcon tube. Then, centrifuged twice at 300xg for 5 min each. The final pellet was re-suspended in appropriate volume (depending on the sperms concentration after washing) of pre-warmed fertilization medium (Fert. TALP medium) then the final sperm concentration was adjusted to $3 \times 10^{6} / \mathrm{ml}$ (El-Sayed et al., 2012). 


\section{Conventional IVF:}

Sperm suspension and matured oocytes were co-incubated in groups of $20-25$ oocytes/ 400 $\mu \mathrm{l}$ fertilization medium at $38.5{ }^{\circ} \mathrm{C}, 5 \% \mathrm{CO}_{2}$ and $95 \%$ humidity in air for $18 \mathrm{~h}$.

\section{ICSI:}

For injection procedure an inverted microscope (DMI 3000B, Leica Microsystems, Wetzlar, Germany) has been used with micromanipulator system (NARISHIGI, Japan).

Amount of $1 \mu \mathrm{l}$ of sperm suspension was added to a $10 \mu \mathrm{l}$ drop of polyvinyl-pyrrolidone (PVP; 10\%, FrtiPro, Belgium) shortly before microinjection. Thereafter, injection was done using a pipette with inner diameter of eight $\mu \mathrm{m}$, and the holding pipette with $25 \mu \mathrm{m}$. Sperms were individually immobilized by targeting the mid piece, aspirated tail-first and injected into the ooplasm through the zona pellucida. The first polar body was adjusted to either six or 12 o'clock position, and the injection pipette adjusted to three o'clock position. During the injection, cytoplasm was aspirated to approve that the oolema was broken. The spermatozoon was injected into the ooplasm with a minimum volume of medium at the 9 o'clock position (Shirazi et al., 2009) as shown in Plate 2.

\section{In vitro culture system:}

After IVF or ICSI, the presumptive zygotes were transferred to a washing medium (TCM199 with HEPES supplemented with $10 \%$ (v/v) heat-treated $\left(56{ }^{\circ} \mathrm{C}\right.$ for $\left.30 \mathrm{~min}\right) \mathrm{FBS}$ and $\mathrm{AA}$ (100 IU penicillin and $100 \mu \mathrm{g}$ streptomycin/ml), then cultured in a modified synthetic oviductal fluid (mSOF) medium supplemented with 5\% FBS and AA (100 IU penicillin and $100 \mu \mathrm{g}$ streptomycin/ml) in groups of 5 embryos per 100 $\mu l$ culture medium. Thereafter, the embryos were incubated at $38.5{ }^{\circ} \mathrm{C}$ in sterile filtered human lung air containing around $4 \%$ carbon dioxide and 16 to $17 \%$ oxygen using submarine incubation system (SIS) as stated by (Vajta et al., 1997).

\section{Statistical analysis:}

Data was statistically analyzed using IBM SPSS 22.0 Software Package (IBM corp., NY, USA, 2013). Independent-Samples $\mathrm{T}$ Test was used to analyze the effect of sperm source (epididymal and frozen), insemination methods (IVF and ICSI) on cleavage and blastocyst rates and to compare the maturation rates due to expansion and polar body for oocytes exposed to $30 \mathrm{~h}$ or $40 \mathrm{~h}$ maturation time. Results are expressed as means \pm S.E.M. and the significance level was set at $\mathrm{P}<0.05$.

\section{RESULTS AND DISCUSSION}

\section{Effect of maturation time}

The maturation rate (83\%) according to expansion of cumulus cells for oocytes incubated for $30 \mathrm{~h}$ was significantly higher $(\mathrm{P}<0.05)$ than that for oocytes incubated for $40 \mathrm{~h}(64 \%)$. In addition, nuclear maturation rate that indicated by extrusion of the first polar body was higher in $30 \mathrm{~h}$ group but not significantly different ( $\mathrm{P}$ $<0.05)$ than $40 \mathrm{~h}$ group as shown in Table 1 . The results are in agreement with those obtained by Khatir et al. (2007) who found that incubation for $30 \mathrm{~h}$ has resulted in $84 \%$ maturation rate. The lower maturation rate resulted from $40 \mathrm{~h}$ maturation, maybe due to the tendency towards a higher percentage of degenerated oocytes as the culture period increased more than $30 \mathrm{~h}$ as reported before by Kafi et al. (2005). On the other side, this result is lower than that obtained by El-Nahla et al. (2014) who recorded maturation rate $92 \%$ for oocytes incubated for 40 $\mathrm{h}$ and average of $80 \%$ extrusion of the first polar body. This discrepancy maybe due to the few numbers of trials which have been done on oocyte maturation testing the incubation time in dromedary especially when different media were used or the experiments were performed in different seasons.

Table 1. Effect of different incubation periods on maturation rate

\begin{tabular}{lcc}
\hline Trait & $\mathbf{4 0 h}$ & $\mathbf{3 0 h}$ \\
\hline No. of oocytes & 157 & 218 \\
Expansion $(\%)$ & $64.3 \pm 4.0^{\mathrm{a}}$ & $83 \pm 2.0^{\mathrm{b}}$ \\
Polar body (\%) & $15.7 \pm 3.0^{\mathrm{a}}$ & $22.7 \pm 2.0^{\mathrm{a}}$ \\
\hline
\end{tabular}

Means within the same row having different superscript letters differ significantly at $(P<0.05)$.

Effect of sperms source and fertilization techniques on cleavage and blastocyst rates:

The results of this study (Table 2 and plate 2) show that the cleavage rate of the in vitro dromedary embryos resulted from fertilization by using epididymal spermatozoa, frozen semen or ICSI were not significant $(\mathrm{P}>0.05)$ where it has recorded $21 \%, 20 \%$ and $23 \%$ respectively. There was no significant difference $(\mathrm{P}>0.05)$ in the proportion of blastocyst resulted from oocytes fertilized with epididymal spermatozoa, frozen semen or ICSI $(8.27 \%, 8.33 \%$ and $5.5 \%$ respectively). The result of epididymal spermatozoa regarding cleavage rate is higher than that obtained (17\%) by Fathi et al. (2014) and it is related to that obtained by Moawad et al. (2012) who reported that the cleavage rate was $26.8 \%$ in in vitro camel embryos. On the 
other side this result using epididymal spermatozoa tended to be low compared to the results $(37 \%-43 \%)$ reported by Wani (2009) and Badr and Abdel-Malak (2010). The blastocyst rate resulted from oocytes fertilized by epididymal spermatozoa is higher than the rate (1.2\%) obtained by Badr and Abdel-Malak (2010) and that (3\%) obtained by Fathi et al. (2014) but comparable to the rate $(10 \%)$ obtained by Wani (2009). The cleavage and blastocyst rates resulted from fertilization by frozen semen is considered to be high compared to the few studies of using frozen semen for in vitro production of camel embryos done by Abdoon et al. (2007) who reported 17\% and 0\% for cleavage and blastocyst rates respectively, and previous study reported by, El-Sayed et al. (2012) who reported $19 \%$ and $3.8 \%$ for cleavage and blastocyst rates respectively. The ICSI results even though the low percentage of blastocyst rate $(5.5 \%)$ but according to the author's knowledge it is considered to be novel in this species.

Table 2. Effect of sperm sources and fertilization techniques on cleavage and blastocyst rates $($ mean \pm S.E)

\begin{tabular}{lccc}
\hline Sperm & $\begin{array}{c}\text { No. of fertilized } \\
\text { oocytes }\end{array}$ & Cleavage rate & Blastocyst rate \\
\hline Epource/technique & 290 & $21.2 \pm 1.7^{\mathrm{a}}$ & $8.27 \pm 2.3^{\mathrm{a}}$ \\
Frozen (G2) & 205 & $20.7 \pm 2.0^{\mathrm{a}}$ & $8.33 \pm 2.5^{\mathrm{a}}$ \\
ICSI (G3) & 28 & $23 \pm 9.3^{\mathrm{a}}$ & $5.5 \pm 5.0^{\mathrm{a}}$ \\
\hline
\end{tabular}

Means within the same column with different superscript letters differ significantly at $(P<0.05)$.

In conclusion, the present results validate for the first time ICSI technique as a successful method for in vitro production of camel embryos with further investigations to enhance the success rate. Moreover, frozen semen could be used for in vitro production of camel embryos with comparable results as epididymal spermatozoa.

\section{ACKNOWLEDGEMENT}

This study has been achieved within the PROCAMED project funded by European Union within the program ENPI-CBC-MED, reference number I.B/1.1/493. The content of the present document is under the responsibility of the PROCAMED partners and could not be considered as the position of European Union.

\section{REFERENCES}

Abdoon, A.S.S., 2001. Factors affecting follicular population, oocytes yield and quality in camels (Camelus dromedarius) ovary with special reference to maturation time in vitro. Animal Reproduction Science, 66(1-2):71-79.

Abdoon, A.S., O.M. Kandil, B. Berisha, H. Kliem and D. Schams, 2007. Morphology of dromedary camel oocytes and their ability to spontaneous and chemical parthenogenetic activation. Reproduction in Domestic Animals, 42(1): 88-93.

Amer, H. and A. Moosa, 2008. Relationship between season of the year, culture medium and in vitro oocyte competence in dromedary camels. Bulgarian Journal of Veterinary Medicine, 11(3): 195- 204.

Badr, M.R. and M. G. Abdel-Malak, 2010. In vitro fertilization and embryo production in dromedary camel using epididymal spermatozoa. Global Veterinaria, 4: 271-276.

El-Bhrawi, K.A., 2005. Reproductive Studies on Desert Animals: Sexual Behaviour and Semen Characteristics and Freezability of Male Dromedary Camels. Ph.D.Thesis. Faculty of Agriculture, Alexandria University, Egypt, 163 p.

El-Nahla, A.M., O.M. Kandil, A.S.S. Abdoon, A.A. Siam and F.A. Al-Monifi, 2014. Effect of season and maturation time on oocyte competence and in vitro maturation of dromedary camel oocyte. Global Veterinaria, 13 (1): 39-46

El-Sayed, A., H.A. Sayed, E.E. El-Hassanein, H. Murad and A.H. Barkawi, 2012. Effect of epidermal growth factor on in vitro production of camel (Camelus dromedarius) embryos by using frozen semen. Egyptian Journal of Animal Production, 49 (Suppl. Issue):39-45

FAOSTAT, 2013. http://faostat3.fao.org/ browse/Q/QL/E

Fathi, M., A.A. Seid, R.R. Sobhy, G.M. Darwish, M.R. Badr and A.R. Moawad, 2014. Caffeine supplementation during IVM improves frequencies of nuclear maturation and preimplantation development of dromedary camel oocytes following IVF. Theriogenology, 81(9):1286-1292.

García-Roselló, E., E. García-Mengual, P. Coy, J. Alfonso and M. A. Silvestre, 2009. Intracytoplasmic sperm injection in livestock species: an update. Reproduction in Domestic Animals, 44(1):143-151.

Gordon, I. 2003. Laboratory Production of Cattle Embryos. $2^{\text {nd }}$ Edition. CAB International, Wallingford, UK. 548p.

Kafi, M., F. Mesbah, H. Nili, A. Khalili, 2005. Chronological and ultrastructural changes in 
camel (Camelus dromedarius) oocytes during in vitro maturation. Theriogenology, 63(9): 2458-2470.

Khatir, H. and A. Anouassi, 2006. The first dromedary (Camelus dromedarius) offspring obtained from in vitro matured, in vitro fertilized and in vitro cultured abattoirderived oocytes. Theriogenology, 65(9):1727-1736.

Khatir, H., A. Anouassi and M. Tibary, 2004. Production of dromedary (Camelus dromedarius) embryos by IVM and IVF and co-culture with oviductal or granulosa cells. Theriogenology, 62(7):1175-1185.

Khatir, H., A. Anouassi, and A. Tibary, 2005. In vitro and in vivo developmental competence of dromedary (Camelus dromedarius) embryos produced in vitro using two culture systems (mKSOMaa and oviductal cells). Reproduction in Domestic Animals, 40(3): 245-249.

Khatir, H., A. Anouassi, and A. Tibary 2007. Quality and developmental ability of dromedary (Camelus dromedarius) embryos obtained by IVM/IVF, in vivo matured/IVF or in vivo matured/fertilized oocytes. Reproduction in Domestic Animals, 42(3):263-70

Moawad, A.R., G.M. Darwish, M.R. Badr and A.B. EL-Wishy, 2012. In vitro fertilization of dromedary camel (Camelus dromedaries) oocytes with epididymal spermatozoa. Reproduction, Fertility and Development, 24(1):192-193

Nowshari, M.A. and N.A. Wani, 2005. Camelid embryo development in vitro: effect of protein supplementation in maturation medium and subsequent culture in two different media on fertilization and development. Reproduction, Fertility and Development, 17(2):276-276

Parrish, J.J., J.L. Susoko-Parrish, M.L. LeibfiedRutledge, E.S. Critser, W.H. Eyestone and N.L. First, 1986. Bovine in vitro fertilization with frozen-thawed semen. Theriogenology, 25(4):591-600.

Probst, S. and D. Rath, 2003. Production of piglets using intracytoplasmic sperm injection (ICSI) with flowcytometrically sorted boar semen and artificially activated oocytes. Theriogenology, 59(3-4):961-973.

Shirazi, A.S. Ostad-Hosseini, E. Ahmadi, B. Heidari and N. Shams-Esfandabadi, 2009. In vitro developmental competence of ICSIderived activated ovine embryos. Theriogenology, 71(2):342-348.

Skidmore, J. A., 2005. Reproduction in dromedary camels: An update. Animal Reproduction, 2(3):161-171.

Suthar, V. S. and R.G. Shah, 2009. Bovine In vitro embryo production: an overview. Veterinary World, 2(12): 478- 479.

Torner, H., B. Heleil, H. Alm, I. Ghoneim, V. Srsen, W. Kanitz, A. Tuchscherer and E.M. Fattouh, 2003. Changes in cumulus-oocyte complexes of pregnant and non-pregnant camels (Camelus dromedarius) during maturation in vitro. Theriogenology, 60(5):977-987.

Vajta, G., P. Holm, T. Greve and H. Callesen, 1997. The submarine incubation system, a new tool for in vitro embryo culture: A technique report. Theriogenology, 48(8):1379-1385.

Wani, N. A. and M. A. Nowshari, 2005. Kinetics of nuclear maturation and effect of holding ovaries at room temperature on in vitro maturation of camel (Camelus dromedarius) oocytes. Theriogenology, 64(1):75-85.

Wani, N.A., 2009. In vitro embryo production in camel (Camelus dromedarius) from in vitro matured oocytes fertilized with epididymal spermatozoa stored at $4{ }^{\circ} \mathrm{C}$. Animal Reproduction Science, 111(1): 69-79. 

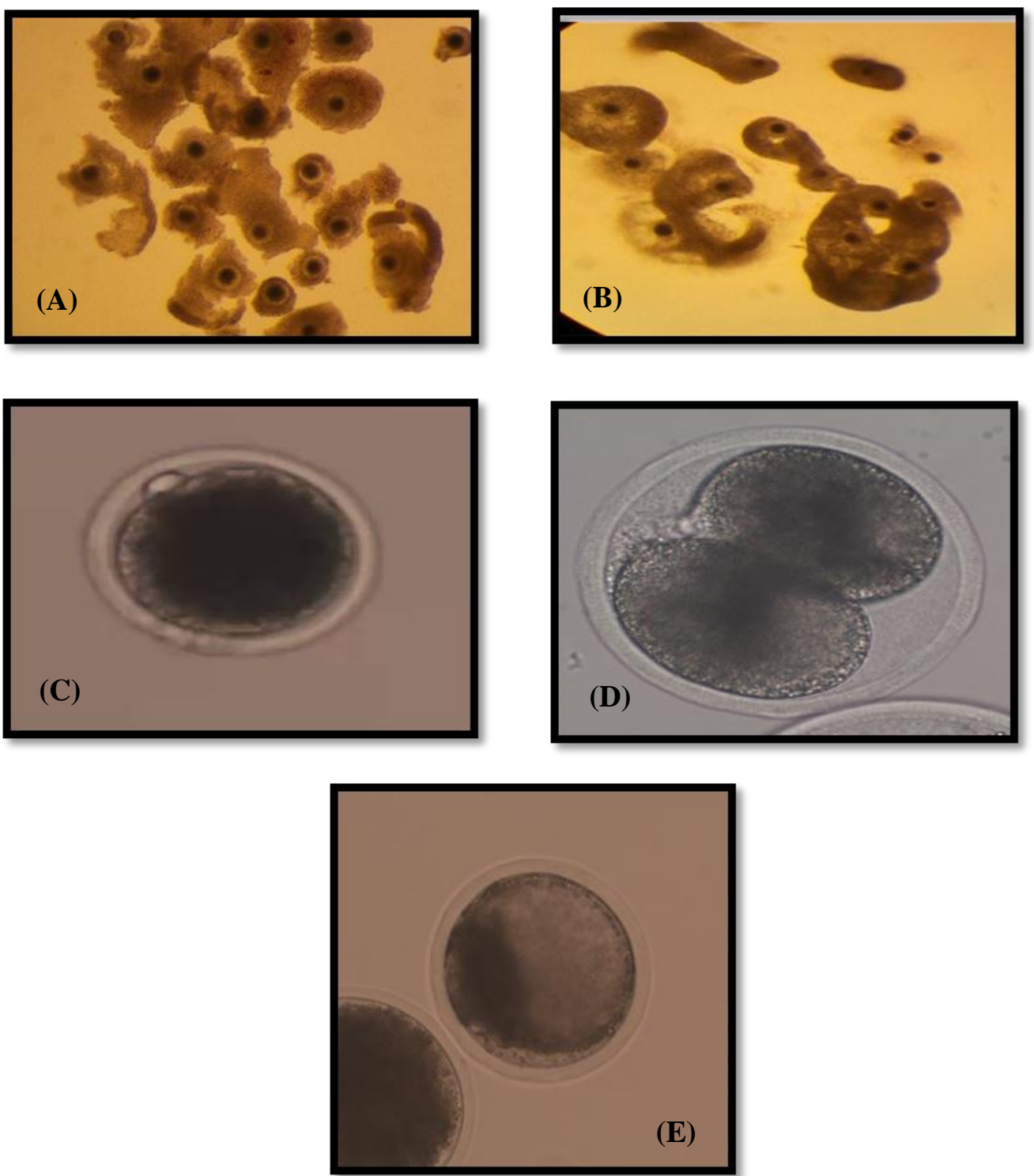

Plate.1. Developmental stages of in vitro produced camel embryos showing: A- immature oocytes, B- mature oocytes with expanded cumulus cells, $\mathrm{C}$ - denuded mature oocyte with $1^{\text {st }}$ polar body, D- 2 cell stage embryo and E- blastocyst. 


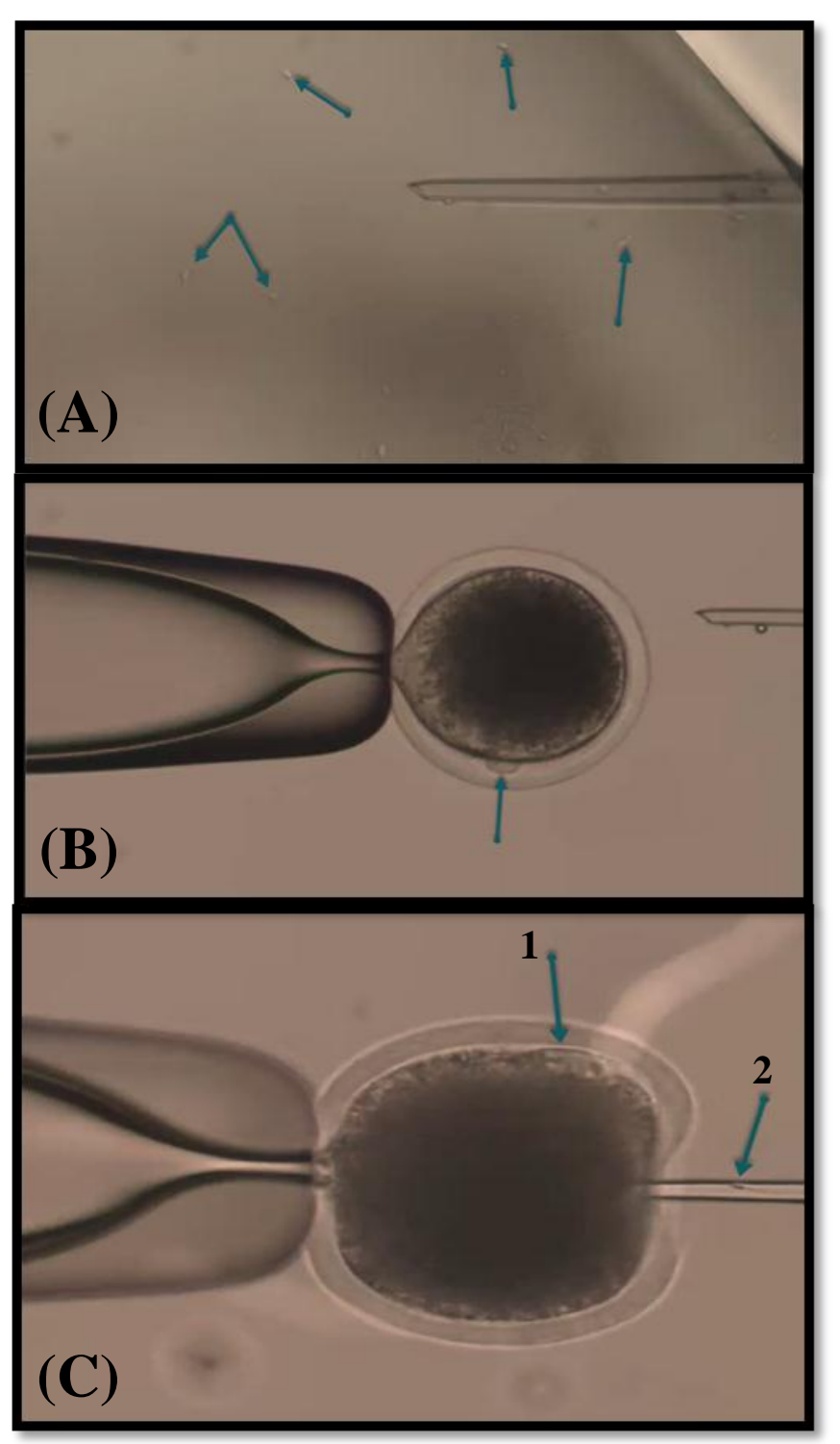

Plate. 2. ICSI process: A- Sperm immobilization (arrows toward sperms) B- Adjusting the polar body to 6 or 12 o'clock (arrow toward polar body) C- Sperm injected into the ooplasm (arrow 1: the polar body to 12 o'clock, arrow 2: injection pipette penetrated the oolema with sperm inside). 


\section{تقييم إنتاج أجنة الإبل معمليا بإستخدام مصدرين للحيوانات المنوية وتقنيتين للاخصاب المعملى}

اشرف السيد "،جمال عاثور '، احمد محمد كامل"، خالد احمد البحراوي”

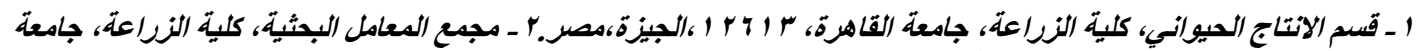

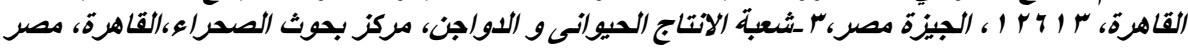

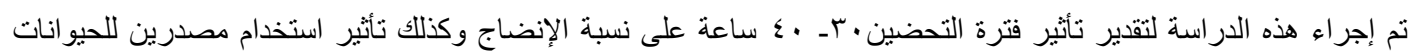

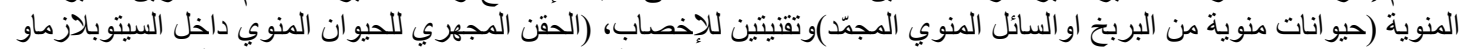

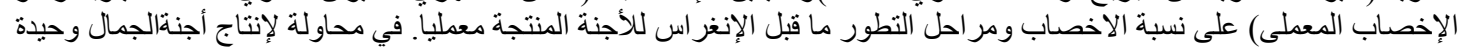

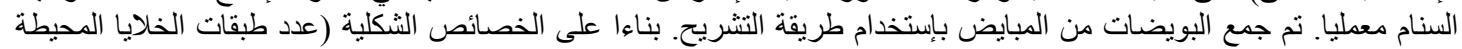

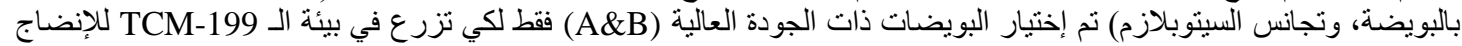

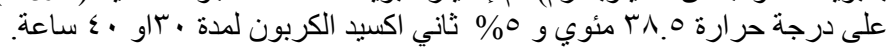

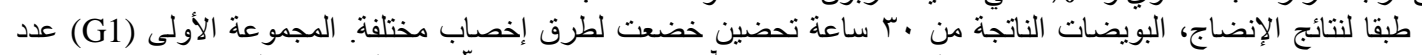

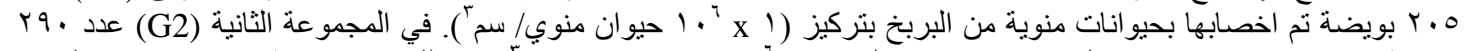

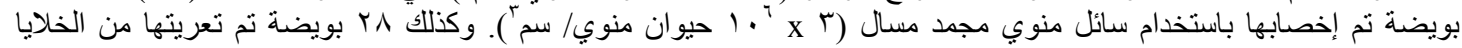

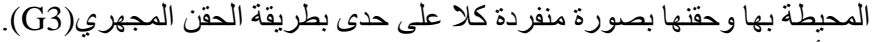

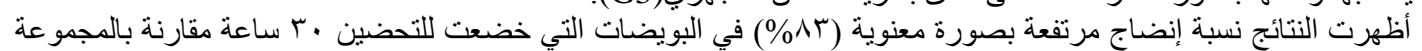

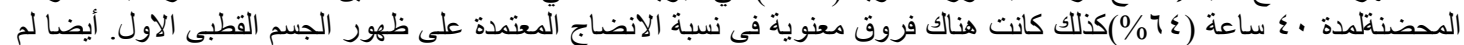

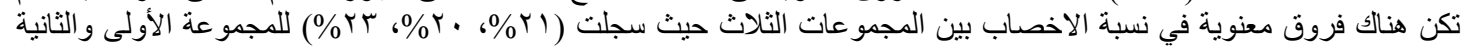

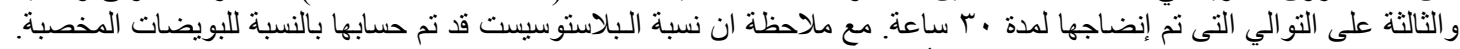

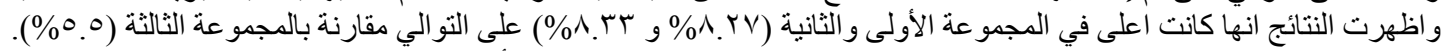

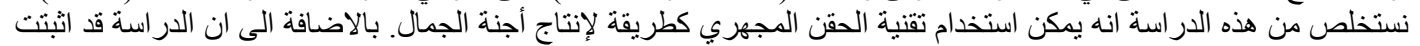

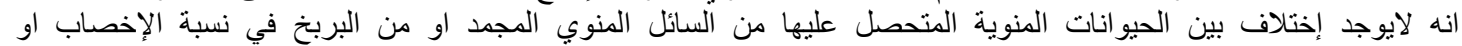
البلاستوسيست عند استخدامهم في الإخصاب المعملي لبويضات الجنات الجمال. 